\title{
Residual dynamics and dietary exposure risk of dimethoate and its metabolite in greenhouse celery
}

\author{
Chunjing Guo ${ }^{1,2}$, Guang $\mathbf{L i}^{1,2}$, Qiujun Lin ${ }^{1,2}$, Xianxin Wu ${ }^{1,2}$, Jianzhong Wang ${ }^{\text {Corresp. } 1,2}$ \\ 1 Institute of Agricultural Quality Standards and Testing Technology, Liaoning Academy of Agricultural Sciences, Shenyang, China \\ 2 Ministry of Agriculture and Rural Affairs Lab of Agricultural Product Quality Safety Risk Assessment (Shenyang), Shenyang, China \\ Corresponding Author: Jianzhong Wang \\ Email address: WJZ721125@sina.com
}

This study aimed to explore the residual dynamics and dietary risk of dimethoate and its metabolite omethoate in celery. Celery was sprayed with 40\% dimethoate EC at either a low concentration of $600 \mathrm{~g}$ a.i./ha or a high concentration of $900 \mathrm{~g}$ a.i./ha. Plants in the seedling, transplanting, or middle growth stages were sprayed once, and the samples were collected 90 days after transplantation. Plants in the harvesting stage were sprayed two or three times. The samples were collected on days 3, 5, 7, 10, 14, and 21 after the last pesticide application. The dimethoate and omethoate compounds were extracted from the celery samples using acetonitrile, and their concentrations were detected using ultraperformance liquid chromatography-tandem mass spectrometry. Also, the dietary risk assessments of dimethoate and omethoate were conducted in various populations and on different foods in China. The metabolism led to the formation of omethoate from dimethoate in the celery. The degradation dynamics of dimethoate and total residues in greenhouse celery followed the first-order kinetic equation. The half-lives of the compounds were 2.42 days and 2.92 days, respectively. The celery which received one application during the harvesting stage had a final residue of dimethoate after 14 days, which was lower than the maximum residue limit (MRL) $0.5 \mathrm{mg} \mathrm{kg}^{-1}$ for Chinese celery. The final deposition of the metabolite omethoate after 28 days was less than the maximum residue limit of $0.02 \mathrm{mg} \mathrm{kg}^{-1}$ for Chinese celery. Furthermore, the risk quotients of dimethoate in celery was less than 1 ; therefore, the level of chronic risk was acceptable after day 21 . Only children aged 2-7 years had an HQ of dimethoate more than 1 (an unacceptable level of acute risk), while the acute dietary risks to other populations were within acceptable levels. It was recommended that any dimethoate applications to celery in greenhouses should happen before the celery reached the harvesting stage, with a safety interval of 28 days. 
1 Residual dynamics and dietary exposure risk of dimethoate and its metabolite in 2 greenhouse celery

3

4 Chunjing Guo ${ }^{1,2}$, Guang $\mathrm{Li}^{1,2}$, Qiujun $\mathrm{Lin}^{1,2}$, Xianxin $\mathrm{Wu}^{1,2}$, Jianzhong Wang ${ }^{* 1,2}$

$5 \quad{ }^{1}$ Institute of Agricultural Quality Standards and Testing Technology, Liaoning Academy of

6 Agricultural Sciences, Shenyang 110161, Liaoning, China

$7 \quad$ Ministry of Agriculture and Rural Affairs Lab of Agricultural Product Quality Safety Risk

8 Assessment (Shenyang), Shenyang 110161, Liaoning, China)

$9 *$ Corresponding author

10 Jianzhong Wang

11 Phone: 024 31021037. Fax: 024 31029902. E-mail: WJZ721125@sina.com 


\section{ABSTRACT}

This study aimed to explore the residual dynamics and dietary risk of dimethoate and its metabolite omethoate in celery. Celery was sprayed with $40 \%$ dimethoate EC at either a low concentration of $600 \mathrm{~g}$ a.i./ha or a high concentration of $900 \mathrm{~g}$ a.i./ha. Plants in the seedling, transplanting, or middle growth stages were sprayed once, and the samples were collected 90 days after transplantation. Plants in the harvesting stage were sprayed two or three times. The samples were collected on days 3, 5, 7, 10, 14, and 21 after the last pesticide application. The dimethoate and omethoate compounds were extracted from the celery samples using acetonitrile, and their concentrations were detected using ultra-performance liquid chromatography-tandem mass spectrometry. Also, the dietary risk assessments of dimethoate and omethoate were conducted in various populations and on different foods in China. The metabolism led to the formation of omethoate from dimethoate in the celery. The degradation dynamics of dimethoate and total residues in greenhouse celery followed the first-order kinetic equation. The half-lives of the compounds were 2.42 days and 2.92 days, respectively. The celery which received one application during the harvesting stage had a final residue of dimethoate after 14 days, which was lower than the maximum residue limit (MRL) $0.5 \mathrm{mg} \mathrm{kg}^{-1}$ for Chinese celery.The final deposition of the metabolite omethoate after 28 days was less than the maximum residue limit of $0.02 \mathrm{mg} \mathrm{kg}^{-1}$ for Chinese celery.

Furthermore, the risk quotients of dimethoate in celery was less than 1; therefore, the level of chronic risk was acceptable after day 21. Only children aged 2 - 7 years had an HQ of dimethoate more than 1 (an unacceptable level of acute risk), while the acute dietary risks to other populations were within acceptable levels. It was recommended that any dimethoate applications to celery in greenhouses should happen before the celery reached the harvesting stage, with a safety interval of 28 days.

Keywords Celery, Dimethoate, Omethoate, Pesticide residues, Dietary risk assessment INTRODUCTION

Celery is a good source of vitamin C, folic acid, carotene, phenols, and flavonoids (Liang et al., 2018), which are known to lower blood pressure (Madhavi et al., 2013) and have antiinflammatory and antioxidant effects in humans and other mammals (Kooti et al., 2017; Powanda et al., 2011). China ranks first in the world in terms of celery production with a planting area of around 550,000 ha (Gao et al., 2014; Madhavi et al., 2013). Pesticides are 
commonly used in celery production to increase crop yield and quality by preventing and reducing the damage caused by diseases and insect pests. It is safe to use acetamiprid, thiamethoxam, imidacloprid, and pymetrozine in celery production according to the Pesticide Fact Sheet. However, the application of dimethoate has potential risks to the environment and human health; therefore, the risk assessments of pesticide residues have received increasing attention (Dai et al., 2019; Dominiak 2019; Kranawetvogl et al., 2018; Rezaei \& Mahdi, 2018).

Dimethoate (Figure 1-A), a broad-spectrum systemic insecticide is widely used to control insect pests in vegetables, fruits, tea trees, wheat and rice (Zheng \& Sun, 2014). It can be degraded into omethoate (Figure 1-B) in plants. Omethoate is a highly toxic pesticide with strong contact and penetration effects (Eddleston et al., 2016; Zhang et al., 2017), and hence it has been banned from use on vegetables in China. However, recent investigations found that the detection rate and over standard rate of this pesticide residues are relatively high in celery (Liu, 2017; Sun et al., 2014; Yaojun et al., 2016). It was believed that the primary cause of this problem might be the production of omethoate as a metabolite when celery was sprayed with dimethoate. Its toxicity is much higher.

In China, the registration PHI of dimethoate in wheat is 14 days, but it is not registered in celery. Since omethoate derives from dimethoate, even if the safety interval of 14 days is safe for dimethoate, it does not mean that the metabolite omethoate is safe. Whether the current safety interval for dimethoate application ensures the residue of its metabolite omethoate to be below the MRL is not clear.. A previous study showed that the safety interval for celery sprayed with dimethoate should be 21 days for the residue of omethoate to be less than the maximum residue limit (MRL) (Guo et al., 2017). Nevertheless, the demand for fresh vegetables in winter increases with the improvement in living standards, resulting in the expansion of the celery plantation area in northern greenhouses and greater use of dimethoate. Therefore, it is vital to monitor dimethoate and omethoate residues in greenhouses to assess human health risks (EFSA, 2016; Van et al., 2016; Zhu et al., 2015).

Although efforts have been put into studying the dynamics of dimethoate in celery (Chen et al., 2018; Lu et al., 2017; Yuan et al., 2014), few reports are available on the degradation dynamics of omethoate residues. This study investigated the dissipation dynamics and residues of dimethoate and omethoate in greenhouse celery. Based on the experimental data, dietary risk assessments were conducted for different populations in China, and the safe application of dimethoate 
in celery was explored.

\section{MATERIALS AND METHODS}

\section{Test materials}

Celery was used as the test crop. The field test was carried out in the vegetable production base in the Liaozhong district of Shenyang City. No extreme weather events, such as heavy rain and hail, were observed during pesticide applications, and the climatic conditions were normal. The test pesticide was 40\% dimethoate EC, Hebei Zhongtian Bangzheng Biologic Science Co., Ltd.. The maximum recommended dose is $600 \mathrm{~g}$ a.i./ha in China. The formulation of dimethoate was analyzed before application in this study. The content of dimethoate met the requirements, and no omethoate was detected in it.

\section{Instruments}

Waters UPLC TQ Ultra Performance Liquid Chromatography-Tandem Mass Spectrometer, Waters, USA; Zhongjia HC 3514 High-Speed Centrifuge, Anhui USTC Zonkia Scientific Instrument Co., Ltd.; Ding Haoyuan RS-1 Vortex Mixer, Beijing Ding-Hao Yuan Technology Co., Ltd.; Pine-tree ultra-pure water machine, Beijing Xiangshunyuan Technology Co., Ltd.; JACTO HD400 Backpack Sprayer, JACTO Agricultural Machinery Co., Ltd.; $0.22 \mu \mathrm{m}$ needle filter, $50 \mathrm{~mL}$ polypropylene plastic centrifuge tube, Xinkang Medical Equipment Co., Ltd..

\section{Reagents}

Methanol, acetonitrile (chromatographically pure), Merck. Wondapak QuEchERS extraction and separation kit, Shimadzu Kojima (Shanghai) Trading Co., Ltd. Dimethoate and omethoate were purchased from the Environmental Quality Supervision and Testing Center of the Ministry of Agriculture (Tianjin).

\section{Standard solutions}

Standard stock solutions $\left(100 \mathrm{mg} \mathrm{L}^{-1}\right)$ of dimethoate and omethoate were diluted with acetonitrile to make the working standard solution of different concentrations $(0.005,0.01,0.02$, $0.05,0.1,0.2$, and $\left.0.5 \mathrm{mg} \mathrm{L}^{-1}\right)$. Additionally, celery samples cultivated in control plots were used as blanks. The stock solution was diluted with the clean control extract to generate the matrix standard solution $\left(0.005,0.01,0.02,0.05,0.1,0.2\right.$, and $\left.0.5 \mathrm{mg} \mathrm{L}^{-1}\right)$. Standard solutions were stored in the dark at $-20^{\circ} \mathrm{C}$. Blanks with a dimethoate and omethoate solution at three concentration levels $\left(0.01,0.1\right.$, and $\left.1 \mathrm{mg} \mathrm{kg}^{-1}\right)$ were employed for the recovery assay. The analytical method's performance parameters, such as linear ranges, limit of quantification (LOQ), 
and limit of detection (LOD), were determined in addition to recovery rates.

\section{Field test design}

According to Guideline's requirements on pesticide residues trials (NY/T 788-2004, 2004), the test plot was designed with a plot area of $30 \mathrm{~m}^{2}$, a buffer zone of $2 \mathrm{~m}$, and three repeat plots, which were randomly arranged. A control area of $30 \mathrm{~m}^{2}$ without pesticide application was also set up to collect control samples.

Dissipation dynamics: Dimethoate was sprayed at $900 \mathrm{~g}$ a.i./ha (1.5 times the maximum recommended dose) using a knapsack sprayer on the surface of celery at the moderate growth stage, and the experiment was repeated on three plots. The samples were collected two hours, 1 day, 3 days, 5 days, 7 days, 10 days, 14 days, 21 days, 28 days, and 42 days after pesticide application.

Final residual dynamics: The pesticide application dose was $600 \mathrm{~g}$ a.i./ha (the maximum recommended dose) and $900 \mathrm{~g}$ a.i./ha (1.5 times the maximum recommended dose), respectively. Dimethoate was sprayed once using a knapsack sprayer on the soil in the seedling stage, and ripe celery samples were collected 145 days after the pesticide application. Dimethoate was sprayed once using a knapsack sprayer on the surface of celery in the transplanting stage, and ripe celery samples were collected at 90 days after the pesticide application. Dimethoate was sprayed once using a knapsack sprayer on the celery surface in the middle growth stage, and samples of ripe celery were collected at 45 days after the pesticide application. Besides, dimethoate was sprayed using a knapsack sprayer on the surface of celery two and three times in the harvesting stage with intervals of 7 days between applications, and the experiment was repeated on three plots. The samples were collected at 3 days, 5 days, 7 days, 10 days, 14 days, and 21 days after the last pesticide application.

The seedling stage is the day of sowing, the transplanting stage is 55 days after sowing, while the middle growth stage is 45 days after transplantation. Finally, ripe celery was collected 90 days after transplantation. The harvesting stage was $62-97$ days after transplantation. The samples were collected 3 days, 5 days, 7 days, 10 days, 14 days, and 21 days after the last pesticide application. The growing stage, day of the pesticide application, and sampling are shown in Figure 2.

Sampling: For this, $2 \mathrm{~kg}$ of standard, damage-free celery samples $2 \mathrm{~cm}$ above the ground were randomly collected from 5 - 12 points in each plot each time. No samples were collected within 
$1380.5 \mathrm{~m}$ of the edge of the field. The samples were placed in polyethylene bags and transported to

139 the laboratory for the next study stage. The samples were homogenized using a blender (Foer

140 Group, Hong Kong Special Administrative Region, China) and stored in a refrigerator at $-18^{\circ} \mathrm{C}$ 141 until use.

\section{Sample analysis}

143 Extraction: First, $10.0 \mathrm{~g}$ of the sample to be tested was weighed and placed in a $50 \mathrm{~mL}$ centrifuge 144 tube. Second, $20.0 \mathrm{~mL}$ of acetonitrile was added to the centrifuge tube and homogenized for 2 min. The QuEChERS extraction separation bag was added with vigorously shaking for 2 min and centrifuged at 10,000 rpm for $5 \mathrm{~min}$. Finally, the solution supernatant was filtered with a $0.22-\mu \mathrm{m}$ filter membrane, and the filtrate was ready to be tested.

\section{Detection}

Chromatographic conditions were as follows: Acquity UPLC HSS T3 column $(100 \mathrm{~mm} \times 2.1$ $\mathrm{mm}, 1.8 \mu \mathrm{m}$ ); column temperature, $25^{\circ} \mathrm{C}$; injection volume, $5 \mu \mathrm{L}$; flow rate, $0.38 \mathrm{~mL} \mathrm{~min}{ }^{-1}$; mobile phase A, water, and mobile phase B, methanol. Gradient elution conditions were as follows: $0-0.25 \mathrm{~min}, 90 \%-5 \% \mathrm{~A} ; 0.25-5.00 \mathrm{~min}, 5 \%-90 \%$ A. Mass spectrometry conditions were as follows: electrospray ion source positive ion mode $(\mathrm{ESI}+)$; ion source temperature, $500{ }^{\circ} \mathrm{C}$; capillary voltage, $1.0 \mathrm{kV}$; nebulizing gas flow rate, $900 \mathrm{~L} \mathrm{~h}^{-1}$; and taper hole anti blow air flow rate, $50 \mathrm{~L} \mathrm{~h}^{-1}$. The scanning method was the multiple reaction monitoring (MRM) mode. The other MS/MS parameters were separately optimized for each target compound and are listed in Table 1.

\section{Dissipation dynamics}

The first-order kinetic equation was used to express the dissolution dynamics of dimethoate and omethoate in celery over time.

$$
\begin{aligned}
& c_{t}=c_{0} e^{-k t} \\
& t_{1 / 2}=\frac{L n 2}{k}
\end{aligned}
$$

where $t$ is time (day), $c_{t}$ is the concentration $\left(\mathrm{mg} \mathrm{kg}^{-1}\right)$ at time $\mathrm{t}$ (days), $c_{0}$ is the initial concentration ( $\left.\mathrm{mg} \mathrm{kg}^{-1}\right), k$ is the degradation rate constant $\left(\right.$ day $\left.^{-1}\right)$, and $t_{1 / 2}$ is the half-life (d).

\section{Final residue}

The toxicological endpoints of dimethoate and its metabolite are the same; therefore, the sum of 
167 residues of dimethoate and omethoate should be considered together for both acute and chronic 168 dietary intake. Omethoate is more toxic than dimethoate. The relative toxicity of omethoate

169

170

171

172

173

174

175

176

177

178

179

180 compared to dimethoate following chronic and acute were found to be about $\sim 3: 1$ and $\sim 6: 1$, respectively (None, 2009).

Sum of dimethoate and $6 \times$ omethoate, expressed as dimethoate (for acute risk assessment);

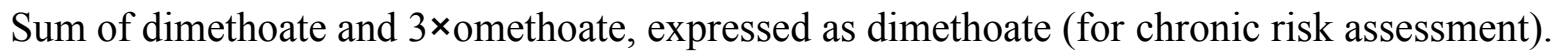
A World Health Organization (WHO) template for evaluating acute exposure (IESTI) is used to evaluate the risk of acute dietary exposure uses. In contrast, a WHO template to evaluate chronic exposure (IEDI) is used to evaluate the risk of chronic dietary exposure.

(http://www.who.int/foodsafety/areas_work/chemical-risks/gems-food/en/).

The following formula (Geng et al., 2018) was used to calculate the risk of chronic dietary exposure of dimethoate and omethoate.

$$
\begin{aligned}
& N E D I=F \times S T M R / b w \\
& R Q=N E D I / A D I
\end{aligned}
$$

where NEDI is the country's estimated daily intake $\left(\mathrm{mg} \mathrm{kg}^{-1} \mathrm{bw} \mathrm{day}{ }^{-1}\right), S T M R$ is the median residue of the standard test $\left(\mathrm{mg} \mathrm{kg}^{-1}\right), F$ is the average food consumption $\left(\mathrm{kg} \mathrm{d}^{-1}\right), b w$ is the body weight $(\mathrm{kg})$, and $A D I$ is the acceptable daily intake $\left(\mathrm{mg} \mathrm{kg}^{-1} \mathrm{bw} \mathrm{day}^{-1}\right) . R Q$ is chronic risk assessment. $R Q>1$ indicates that the chronic dietary intake risk is unacceptable. $R Q<1$ suggests that the chronic nutritional intake risk is acceptable; the smaller the risk quotient (RQ), the lower the risk.

The following formula was used to calculate the risk of acute dietary exposure of dimethoate (the single weight of unprocessed food was more than $25 \mathrm{~g}$, and the edible portion's available weight was more than or equal to the consumption by most individuals) (Geng et al., 2018).

$$
\begin{aligned}
& I E S T I=L P \times H R \times v / b w \\
& H Q=I E S T I / A R f D
\end{aligned}
$$

where IESTI is the estimated short-term intake $\left(\mathrm{mg} \mathrm{kg}^{-1}\right.$ bw day $\left.{ }^{-1}\right), L P$ is the average food consumption $\left(\mathrm{kg} \mathrm{d}^{-1}\right), H R$ is the highest residue obtained in the test $\left(\mathrm{mg} \mathrm{kg}^{-1}\right), v$ is the variability factor assigned a value of 3 according to JMPR (Gao et al., 2007), bw is the body weight (kg), and $A R f D$ is the acute reference dose $\left(\mathrm{mg} \mathrm{kg}^{-1} \mathrm{bw} \mathrm{day}-1\right) . H Q$ is an acute risk assessment. When $H Q<1$, which means that the risk of acute dietary intake is acceptable. When $H Q>1$, it 
197 indicates an unacceptable acute risk.

\section{RESULTS}

199

200

\section{Method validation}

The limits of detection (LODs) and the limits of quantification (LOQs) for dimethoate and omethoate were considered to be the concentrations produced at a signal-to-noise $(\mathrm{S} / \mathrm{N})$ ratio of 3 and 10, respectively. The LODs for the two target chemicals were $0.003 \mathrm{mg} \mathrm{kg}^{-1}$, and the LOQs were $0.01 \mathrm{mg} \mathrm{kg}^{-1}$. Good linear calibration curves were obtained over the concentration range of $0.005-0.5 \mathrm{mg} \mathrm{L}^{-1}$ for dimethoate and omethoate and the correlation coefficient $\mathrm{r}$ was higher than 0.99 (Table 2). The sample concentrations outside the linear range were diluted to the appropriate analytical concentration. The matrix effect (ME) was calculated:

$\operatorname{ME}(\%)=\left(\right.$ slope $\left._{\text {ratio }}-1\right) \times 100 \%$

slope $_{\text {ratio }}=$ slope $_{\text {matrix }} /$ slope $_{\text {solvent }}$

where slope matrix and slope solvent are the calibration curve slopes of the celery and acetonitrile standard, respectively. The matrix effects (MEs) were - 4\% (Table 2), which caused the signal's suppression. Thus, matrix-matched calibration solutions were used to compensate for errors associated with matrix-induced calibration.

The accuracy was evaluated by determining the recovery assay at three levels in celery. No dimethoate and omethoate were detected in the blanks. The mean recoveries were $83.4 \%$ $92.9 \%$ and $80.4 \%-94.6 \%$ for dimethoate and omethoate, with RSD in the range of $3.7 \%-4.5 \%$ and $4.0 \%-7.3 \%$, respectively (Table 3 ). This finding indicated that the method of analysis was accurate and precise.

\section{Dimethoate dissipation dynamics in celery}

The results of dimethoate detection were expressed as average values of three repeat plots. As shown in Figure 3 (when the safety interval was more than 28 days, and the concentration of dimethoate was lower than the LOQ), the degradation of dimethoate met the first-order kinetic equation, $\mathrm{Ct}=4.0499 \mathrm{e}^{-0.286 t}$, and the correlation coefficient $\mathrm{r}^{2}$ was 0.9943 . The half-life was 2.42 days, indicating that dimethoate was an easily degradable pesticide. Ten days later, the dissipation rate reached $94.6 \%$, and the residual concentration of dimethoate decreased to less than $0.5 \mathrm{mg} \mathrm{kg}^{-1}$ (the MRL of dimethoate on celery is $0.5 \mathrm{mg} \mathrm{kg}^{-1}$ ), which was lower than the MRL. Furthermore, the dissipation rate reached $99 \%$ after 16.1 days. 


\section{Omethoate dissipation dynamics in celery}

228 The results of omethoate detection were expressed as average values of three repeat plots. The

229

230

231

232

233

234

235

236

237

238

239

240

241

242

243

244

245

246

247

248

249

250

251

252

253

254

255

256

257 dissipation data fitting is shown in Figure 4 (when the safety interval was more than 42 days, the concentration of omethoate was lower than the LOQ). Before application, the formulation of dimethoate was analyzed, and no omethoate was detected in it. However, omethoate was detected in the celery. After the application of dimethoate, the concentration of omethoate increased to $0.19 \mathrm{mg} \mathrm{kg}^{-1}$ on day 3 and gradually decreased after 3 days. This finding indicated that the levels of omethoate present in the celery were high due to dimethoate metabolism. After 28 days, the omethoate concentration was less than $0.02 \mathrm{mg} \mathrm{kg}^{-1}$, which was lower than the allowable MRL of omethoate in celery. Hence, a 10 day safety interval was sufficient to ensure that the dimethoate concentration in celery declined to safe levels but was not enough for the omethoate concentration to reach safe levels. A safety interval of 28 days after dimethoate application is recommended based on the MRL $\left(0.02 \mathrm{mg} \mathrm{kg}^{-1}\right)$ of omethoate in Chinese celery. As shown in Figure 5, the dissipation behavior of total residues of dimethoate and its metabolite omethoate conformed to the first-order kinetic equation, $C_{t}=3.7599 \mathrm{e}^{-0.237 t}$, the correlation coefficient $\mathrm{r}^{2}$ was 0.9814 . The half-life was 2.92 days, which was $20.1 \%$ longer than that of parent compound dimethoate. This finding indicated that omethoate should be taken into account in risk assessment as a metabolite of dimethoate.

Final residues following pesticide treatments in seedling, transplanting, and middle growth stages

The final residues of dimethoate and its metabolite omethoate after application in the seedling, transplanting, and middle growth stages of celery are shown in Table 4 . The data showed that both residues of dimethoate and omethoate in celery were lower than the LOQ and the MRLs (the MRL of dimethoate is $0.5 \mathrm{mg} \mathrm{kg}^{-1}$, and the MRL of omethoate is $0.02 \mathrm{mg} \mathrm{kg}^{-1}$ ).

\section{Final residues following pesticide treatments in the harvesting stage}

The samples were collected at 3 days, 5 days, 7 days, 10 days, 14 days, and 21 days after the last pesticide application. The final residues of dimethoate and omethoate are shown in Tables 5and 6. The data showed that, the residue of dimethoate in celery was lower than the allowable MRL of $0.5 \mathrm{mg} \mathrm{kg}^{-1}$ after 10 days when two different dosages of dimethoate were sprayed two or three times. However, omethoate concentration was still higher than the allowable MRL of 0.02 $\mathrm{mg} \mathrm{kg}^{-1}$ after 21 days. Additionally, celery sprayed three times with the same dimethoate 
258

259

260

261

262

263

264

265

266

267

268

269

270

271

272

273

274

275

276

277

278

279

280

281

282

283

284

285

286

287

concentration had higher residues of dimethoate and omethoate compared with celery sprayed only twice, showing a cumulative effect of repeated pesticide application. However, whether the concentration of omethoate had declined to a level below the MRL by this stage could not be determined because a sample of celery 28 days after the final pesticide application was not collected.

\section{Chronic dietary risk assessment}

A safety interval of 28 days after dimethoate application is recommended based on the MRL of omethoate in Chinese celery. The dietary intake risk was not calculated at different times in this study. The standard trial median residue of the total of dimethoate and omethoate in celery is shown in Table 7. The allowable daily intake of dimethoate is $0.002 \mathrm{mg} \mathrm{kg}^{-1} \mathrm{bw}$ (GB 2763-2016, 2016). The daily consumption of vegetables is estimated based on the Chinese dietary structure ( $W u$ et al., 2018; Liu et al., 2018). The daily intake of celery is lower than the total vegetable intake.

Suppose the daily total vegetable intake replaces the celery intake. In that case the calculated dietary risk of the total residual of dimethoate and omethoate is acceptable in vegetable. The dietary risk of the total residual of dimethoate and omethoate in celery is acceptable.

The risk quotient (RQ) was calculated using the chronic dietary risk formulas 3 and 4 . The results (Table 7) showed that on day 10, the RQs of dimethoate were both more than one, and therefore, the risks were unacceptable. On day 14, some RQs of dimethoate were more than 1 (2 - 12 years and $51-65$ years/female), and the risks were unacceptable. After day 21, the RQs of dimethoate in celery were less than one, and the risk was acceptable.

\section{Acute dietary risk assessment}

The acute reference dosages (ARfD) of dimethoate is $0.01 \mathrm{mg} \mathrm{kg}^{-1} \mathrm{bw}$ (Geng et al., 2018; Utture et al., 2012). The HQ was calculated based on the dietary structures of different populations in China (Wu et al., 2018) using the acute dietary risk assessment formulas 5 and 6 to judge the level of acute dietary risk (Table 8). The results showed that the HQ range of dimethoate was $2.42-4.15$ on day 10 . On day 14 , the HQ of dimethoate was $1.22-2.09$. On day 21 , the HQ of dimethoate was $0.67-1.14$. On days 10 and 14, the HQs of dimethoate were more than one and the acute risks were unacceptable. On day 21 , only children aged $2-7$ years had an HQ of dimethoate more than 1 (an intolerable level of risk), while the acute dietary threats to other populations were within acceptable levels. As a precaution, it was recommended that large 
288

289

290

291

292

293

294

295

296

297

298

299

300

301

302

303

304

305

306

307

308

309

310

311

312

313

314

315

316

317

318

amounts of single types of food should not be included in for children aged $2-7$ years in the short term to reduce acute dietary risk.

\section{DISCUSSION}

This study found that the dissipation of dimethoate and total residues in greenhouse celery conformed to the first-order kinetic equation, with $\mathrm{r}^{2}$ equal to 0.9943 and 0.9814 , respectively, and half-lives of 2.42 days and 2.92 days, respectively.

Previous studies found that the half-lives of dimethoate in the open field was 2.5 days (Guo et al., 2017), indicating that the residual levels of dimethoate were not significantly different in the greenhouse and in the field. The half-life of dimethoate in mango is 2 days (Bhattacherjee et al., 2016), and the half-life in cucumber is 5.2 days (Geng et al., 2018), indicating that the dissipation of dimethoate is related to the matrix on which it is applied. The half-life of dimethoate in celery grown in Guizhou is 5.4 days, and the half-life of celery in Anhui is 3.5 days (Chen et al., 2018). Nevertheless, the dissipation of dimethoate was faster in Liaoning (85\%) than in Guizhou (75\%) and Anhui (70.27\%) 7 days after application, indicating that the half-life of dimethoate was also related to region and climate.

As shown in the final residue results, spraying dimethoate's safety risks in the seedling, transplanting, and moderate growth stages were within acceptable limits. Specifically, the residue of dimethoate dropped to less than its MRL 14 days after the last application in the harvesting stage. Still, the residue of omethoate remained far higher than its MRL. Hence, dimethoate application's safety interval should be at least 28 days, which is similar to the respective safety intervals of 27 days for cucumber (Geng et al., 2018), and 30 days for pomegranate (Utture et al., 2012).

The results of the dietary risk assessments showed that after day 21, the RQs of dimethoate in celery were less than one and so the level of chronic risk was acceptable. Only children aged 2 7 years had an HQ of dimethoate more than 1 (an unacceptable level of acute risk), while the acute dietary risks to other populations were within acceptable levels. Furthermore, from a toxicology perspective, the celery would be safe to eat at this safety interval even if the residual concentration of omethoate in celery was higher than the corresponding MRL. Poland and France have made similar assessments of exposure risks for dimethoate and omethoate in other foods (Nougadère et al., 2014; Pawet et al., 2015).

CONCLUSION 
This study showed that the application of dimethoate to greenhouse-grown celery resulted in omethoate residues exceeding the acceptable levels. Any applications of dimethoate to celery in greenhouses should be performed with a 28-day safety interval that ensures adequate levels of omethoate. As a precaution, it is recommended that large amounts of single types of food should be avoided in diets for children $2-7$ years of age to reduce their dietary risk. This finding provided data to support the risk assessments of dimethoate and omethoate in celery and other foods. Although the standard residue test in this study was conducted in the Liaoning district, it provided the basis for testing in other regions of northern China. More importantly, the multiple-year residual data in many places may be combined to make these assessments more accurate.

ACKNOWLEDGMENTSThe authors would like to thank Dr Tianya Li from the College of Plant Protection, Shenyang Agricultural University, for critical reading of the manuscript.

\section{REFERENCES}

Bhattacherjee A K, Dikshit A. 2016. Dissipation kinetics and risk assessment of thiamethoxam and dimethoate in mango. Environmental Monitoring and Assessment. 188: 1-6.

Chen Y L, Zhang Q T, Wang S Y, Yang Y, Meng B H, Hu D Y, Lu P. 2018. Residue dynamics and risk assessment of dimethoate in sweet potato, purple flowering stalk, Chinese kale, celery, and soil. Human and Ecological Risk Assessment. 24: 767-783.

Dai P, Jack C J, Mortensen A N, Bustamante T A, Bloomquist J R, Ellis J D. 2019. Chronic toxicity of clothianidin, imidacloprid, chlorpyrifos, and dimethoate to $\backslash \mathrm{r}$ Apis mellifera $\mathrm{L} \backslash \mathrm{r}$. larvae reared in $\backslash \mathrm{r}$ vitro. Pest Management Science. 75: 29-36.

Dominiak B C. 2019. Components of a systems approach for the management of Queensland fruit fly Bactrocera tryoni (Froggatt) in a post dimethoate fenthion era. Crop Protection. 116: 56-67.

\section{Eddleston M, Mohamed F, Davies J O J, Eyer P, Worek F, Sheriff M H R, Buckley N A.} 2006. Respiratory failure in acute organophosphorus pesticide self-poisoning. Qjm. 99: 513522.

European Food Safety Authority (EFSA). 2016. Prioritised review of the existing maximum residue levels for dimethoate and omethoate according to Article 43 of Regulation (EC) No 396/2005. EFSA Journal. 14: 4647.

Gao G X, Wang W T, Wu F, Liu H J, Wang L B, Lang L, Zhou Y H, Wang Q. 2014. Development Changes and Breeding Strategies of Celery Production in China. Journal of 
350

351

352

353

354

355

356

357

358

359

Changjiang Vegetables. 1-4.

Gao R J, Chen L Z, Zhang W J. 2007. Review on Pesticide Residues Acute Dietary Risk Assessment. Food Science. 28: 363-368.

Geng Y, Jiang L, Zhang Y, He Z, Wang L, Peng Y, Wang Y, Liu X, Xu Y. 2018. Dissipation, pre-harvest interval estimation, and dietary risk assessment of carbosulfan, dimethoate, and their relevant metabolites in greenhouse cucumber (Cucumis sativus L.). Pest Management Science. 74: 1654-1663.

Guideline on pesticide residues trials, NY/T 788-2004; Ministry of Agriculture of the People's Republic of China, China Agriculture Press: Beijing, 2004.

Guo C J, Wang J Z, Li G, Lin Q J. 2017. Residual Dynamics and Safety Assessment of Dimethoate and Omethoate in Outdoor Celery. Journal of Agriculture. 8: 11-14.

Kooti W, Daraei N. 2017. A Review of the Antioxidant Activity of Celery ( Apium graveolens L). Journal of Evidence-based Complementary \& Alternative Medicine. 22: 1029-1034.

Kranawetvogl A, Siegert M, Eyer F, Thiermann H, John H. 2018. Verification of organophosphorus pesticide poisoning: Detection of phosphorylated tyrosines and a cysteineproline disulfide-adduct from human serum albumin after intoxication with dimethoate/omethoate. Toxicology Letters. 299: 11-20.

Liang Y, Li Y, Shi W, Lu Y, Ding Y, Liu X J. 2018. Differences of nutrients and antioxidant activities among different species of celery. Science and Technoogy of Food Industy. 39: 6669, 98 .

Liu H. 2017. Analysis of Vegetable Safety Control in Liaoning. Agricultural Science \& Technology and Equipment. 48-52.

Liu Y P, Luo X W, Chen W R, Zheng Z T, Zhu G Y, Jian Q, Qin D M, Liao X L, Li X G. 2018. Residues behavior and dietary intake risk assessment of malathion in Cucurbita pepo L.. Chinese Journal of Pesticide Science. 020: 232-238.

Lu P, Li J, Chen Y L, Meng B H, Zhang Q T, Hu D Y. 2017. Determination and Risk Assessment of Dimethoate and its Metabolite in Celery Using Liquid Chromatography-tandem Mass Spectrometry. Journal of Guizhou University (Natural Sciences). 34: 21-24, 34.

Madhavi D, Kagan D, Rao V, Murray MT. 2013. A pilot study to evaluate the antihypertensive effect of a celery extract in mild to moderate hypertensive patients. Natural Medicine Journal 4:1-3.

National food safety standard-Maximum residue limits for pesticides in food, GB 2763-2016; 
National Health and Family Planning Commission of the People's Republic of China, Ministry of Agriculture of the People's Republic of China and China Food and Drug Administration, Standards Press of China: Beijing, 2016.

None. 2009. MRLs of concern for the active substances dimethoate and omethoate. Efsa Journal. $7: 172 \mathrm{r}$.

Nougadère A, Merlo M, Héraud F, Réty J, Truchot E, Vial G, Cravedi J P, Leblanc J C. 2014. How dietary risk assessment can guide risk management and food monitoring programmes: The approach and results of the French Observatory on Pesticide Residues (ANSES/ORP). Food Control. 41: 32-48.

Pawel S, Ludwicki J K, Góralczyk K, Czaja K, Hernik A, Liszewska M. 2015. Risk assessment for pesticides' MRL non-compliances in Poland in the years 2011-2015. Roczniki Państwowego Zak adu Higieny. 66: 309-317.

Powanda M C, Rainsford K D. 2011. A toxicological investigation of a celery seed extract having anti-inflammatory activity. Inflammopharmacology. 19: 227-233.

Rezaei S M, Mahdi B. 2018. Effects of dimethoate alone and in combination with Bacilar fertilizer on oxidative stress in common carp, Cyprinus carpio. Chemosphere. 208: 101-107.

Sun J, Wen Y J, Gao J H, Xiao Z Y. 2014. Analysis for Pesticide Residue Monitoring in Celery. Journal of Agricultural Resources and Environment. 31: 151-154.

Utture S C, Banerjee K, Kolekar S S, Dasgupta S, Oulkar D P, Patil A H, Wagh S S. Adsule P G, Anuse M A. 2012. Food safety evaluation of buprofezin, dimethoate and imidacloprid residues in pomegranate. Food Chemistry. 131: 787-795.

Van S A, Pennell A, Zhang X Y. 2016. Environmental Fate and Toxicology of Dimethoate. Reviews of environmental contamination and toxicology. 237: 53-70.

Wu, Y. N.; Zhao, Y. F.; Li, J. G. 2018. The fifth China total diet study. Beijing: Science Press. Yaojun M A. 2016. Detection and Analysis of Pesticide Residue in Celery in Shanxi Province. Journal of Shanxi Agricultural Sciences. 44: 1181-1183.

Yuan D W, Lv W G, Li S X, Zheng X Q, He Q Y, Zhang J Q. 2014. Study on the Degradation of Pesticides Residues in a Closed Environment. Chinese Agricultural Science Bulletin. 30: 317-320.

Zhang C, Lin B, Cao Y, Guo M, Yu Y. 2017. Fluorescence Determination of Omethoate Based on a Dual Strategy for Improving Sensitivity. Journal of Agricultural and Food Chemistry. 65: 
$413 \quad 3065-3073$.

414 Zheng G L, Sun J L. 2014. Modern Pesticide Application Technology Series: Insecticide.

415 Beijing: Chemical Industry Press.

416 Zhu G Y, Wu L F, Zheng Z T, Fu Q M, Duan L F, Gong Y. 2015. Progresses on the Codex

417 Alimentarius Commission schedule and priority lists of pesticides from 2015-2019. Chinese

418 Journal of Pesticide Science. 17: 371-383. 
Figure 1

Chemical structure of dimethoate and omethoate

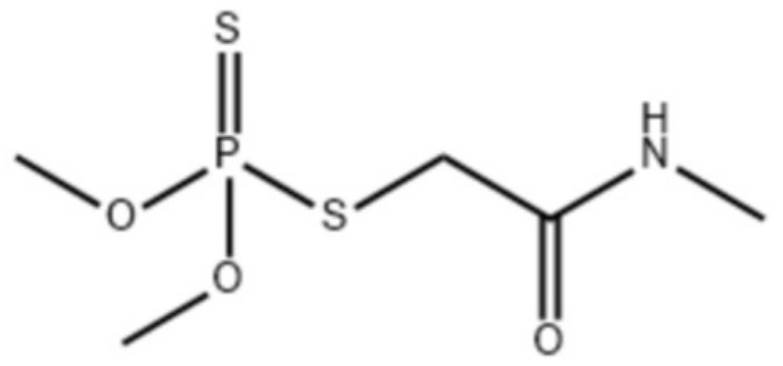

A dimethoate

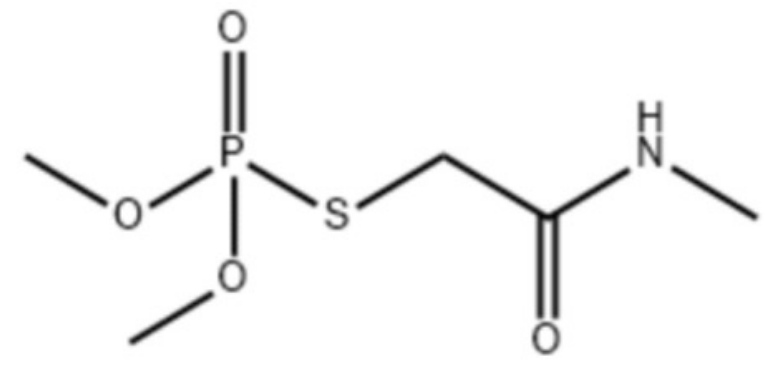

B omethoate 
Figure 2

Growing stage, day of the pesticide application and sampling

\begin{tabular}{|c|c|c|c|c|c|c|}
\hline ck & 55 & 45 & 17 & 7 & 7 & 21 \\
\hline T1 & 55 & \multicolumn{2}{|l|}{45} & 7 & 7 & 21 \\
\hline $\mathrm{T} 2$ & 55 & \multicolumn{2}{|l|}{45} & 7 & 7 & 21 \\
\hline T3 & 55 & \multicolumn{2}{|l|}{45} & 7 & 7 & 21 \\
\hline \multirow[t]{2}{*}{$\mathrm{T} 4$} & 55 & \multicolumn{2}{|l|}{45} & 7 & 7 & 21 \\
\hline & & & & & & \multirow{2}{*}{21} \\
\hline \multirow[t]{6}{*}{ T5 } & 55 & \multirow[t]{2}{*}{45} & 17 & 7 & 7 & \\
\hline & & & & & & 5710 \\
\hline & The seedling stage & $\uparrow$ & \multicolumn{4}{|c|}{ Day of the pesticide application } \\
\hline & The transplanting stage & \multirow[b]{2}{*}{$\uparrow$} & \multirow[b]{2}{*}{ Sampling } & & & \\
\hline & The middle growth stage & & & & & \\
\hline & The harvesting stage & & & & & \\
\hline
\end{tabular}


Figure 3

\section{Level of dimethoate in celery}

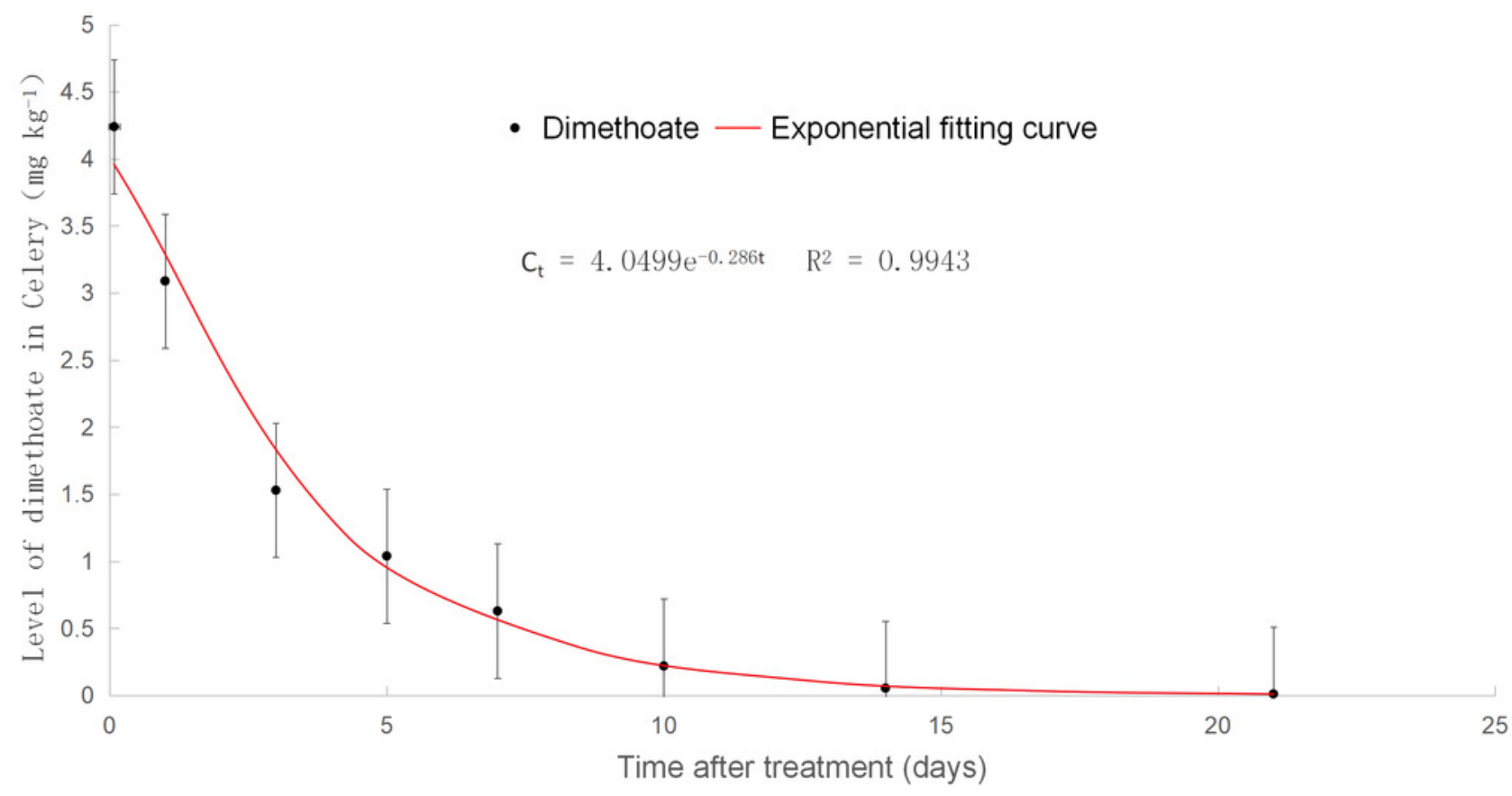


Figure 4

\section{Level of omethoate in celery}

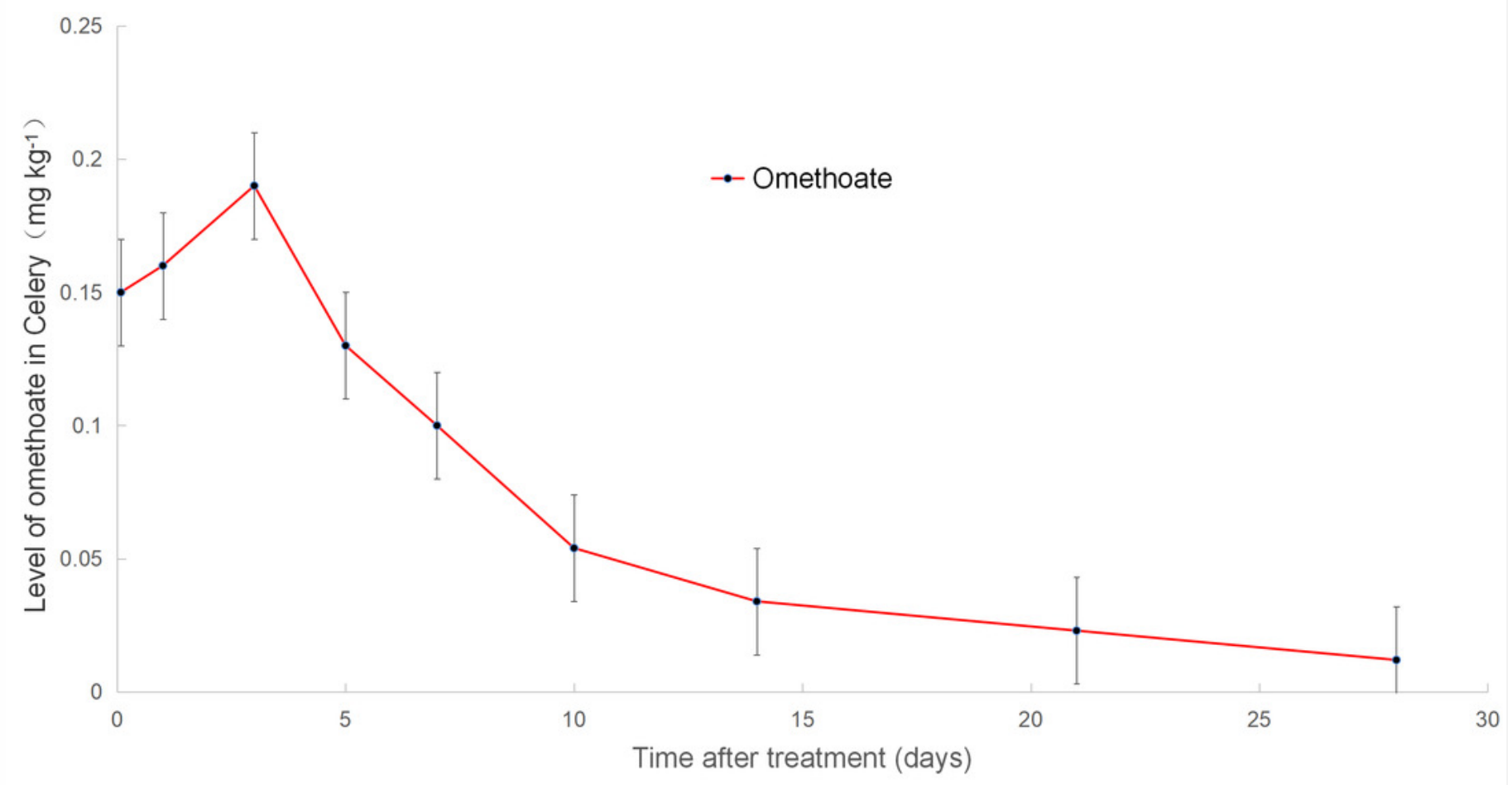


Figure 5

Level of dimethoate and its metabolite in celery

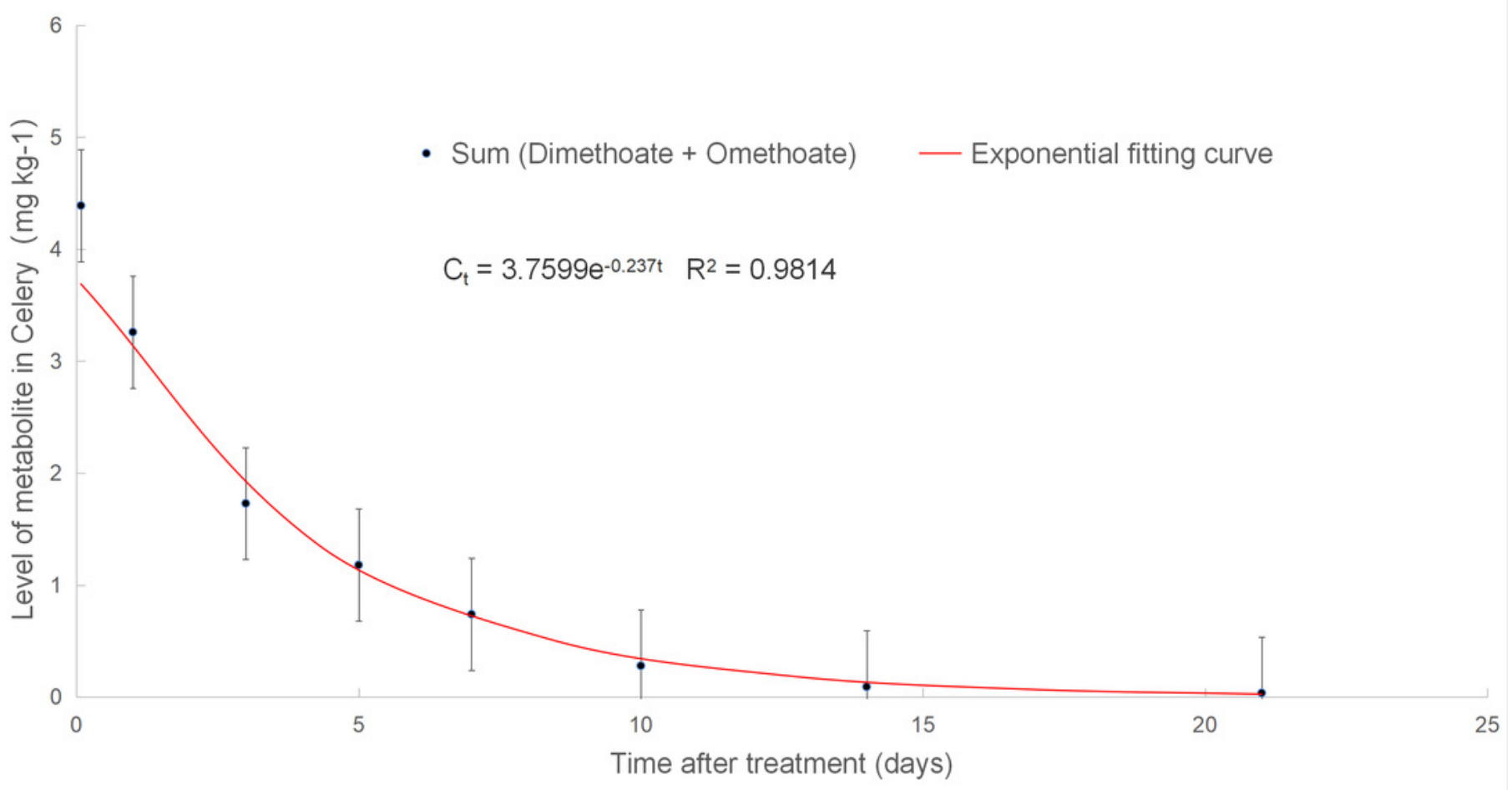




\section{Table 1 (on next page)}

Details of tandem mass spectrometry parameters of dimethoate and omethoate 
1

\begin{tabular}{lcccc}
\hline Pesticide & Precursor ion, $\mathrm{m} / \mathrm{z}$ & Product ion, $\mathrm{m} / \mathrm{z}$ & Collision energy, eV & Declustering potential, V \\
\hline Dimethoate & 230.0 & 125.2 & 12 & 20 \\
& 230.0 & 199.3 & 12 & 10 \\
Omethoate & 214.4 & 125.1 & 15 & 20 \\
& 214.4 & 183.2 & 15 & 11 \\
\hline
\end{tabular}

2 


\section{Table 2 (on next page)}

Linear regression parameters of the calibration curve for dimethoate and omethoate in pure solvent and matrices 
1

2

\begin{tabular}{ccccccc}
\hline Compounds & Matrix & Range $\left(\mathrm{mg} \mathrm{L}^{-1}\right)$ & Regression equation & $\mathrm{R}$ & Slope ratio & ME (\%) \\
\hline Dimethoate & acetonitrile & $0.005-500$ & $y=146.345 x+41.4$ & 0.9992 & - & - \\
& Celery* & $0.005-500$ & $y=141.177 x+226$ & 0.9993 & 0.96 & -4 \\
Omethoate & acetonitrile & $0.005-500$ & $y=35.019 x+64.79$ & 0.9986 & - & - \\
& Celery* & $0.005-500$ & $y=33.5158 x+172$ & 0.9960 & 0.96 & -4 \\
\hline
\end{tabular}

$3 *^{*}$ Celery samples cultivated in control plots were used as blanks. The stock solution was diluted with the clean 4 control extract to generate the matrix standard solution. 


\section{Table 3(on next page)}

Recoveries and relative standard deviations (RSDs) of dimethoate, and omethoate in celery at different fortification levels $(n=6)$ 
1

\begin{tabular}{lccc}
\hline Pesticide & Fortification $\left(\mathrm{mg} \mathrm{kg}^{-1}\right)$ & \multicolumn{2}{c}{ Celery } \\
& & Mean Recovery (\%) & RSD (\%) \\
\hline Dimethoate & 0.01 & 83.4 & 3.7 \\
& 0.1 & 86.6 & 4.5 \\
Omethoate & 1 & 92.9 & 4.0 \\
& 0.01 & 80.4 & 4.0 \\
& 0.1 & 88.8 & 7.2 \\
\hline
\end{tabular}

2 


\section{Table 4 (on next page)}

Residues of dimethoate and its metabolite omethoate after application during seedling stage, transplanting stage and middle stage of growth the celery* 
1

\begin{tabular}{ccccc}
\hline Pesticide & $\begin{array}{c}\text { Dosage } \\
(\mathrm{g} \mathrm{a.i} / \mathrm{ha})\end{array}$ & $\begin{array}{c}\text { Final residue during seedling stage } \\
\left(\mathrm{mg} \mathrm{kg}^{-1}\right)\end{array}$ & $\begin{array}{c}\text { Final residue during transplanting stage } \\
\left(\mathrm{mg} \mathrm{kg}^{-1}\right)\end{array}$ & $\begin{array}{c}\text { Final residue during middle stage of growth } \\
\left(\mathrm{mg} \mathrm{kg}^{-1}\right)\end{array}$ \\
\hline Dimethoate & 600 & $<0.01$ & $<0.01$ & $<0.01$ \\
& 900 & $<0.01$ & $<0.01$ & $<0.01$ \\
Omethoate & 600 & $<0.01$ & $<0.01$ & $<0.01$ \\
& 900 & $<0.01$ & $<0.01$ & $<0.01$ \\
\hline
\end{tabular}

2

* Seedling stage (145 days), transplanting stage (90 days) and middle stage of growth the celery (45 days) 


\section{Table 5 (on next page)}

Residues of dimethoate and its metabolite omethoate after the application of dimethoate two times during harvesting stage of growth the celery 
1

2

\begin{tabular}{|c|c|c|c|c|c|c|c|}
\hline \multirow{2}{*}{ Pesticide } & \multirow{2}{*}{ Dosage(g a.i./ha) } & \multicolumn{3}{|c|}{ Final residue $\left(\mathrm{mg} \mathrm{kg}^{-1}\right)$} & \multicolumn{3}{|c|}{ (Days after the last application) } \\
\hline & & 3 & 5 & 7 & 10 & 14 & 21 \\
\hline \multirow[t]{8}{*}{ Dimethoate } & 600 & 1.60 & 1.15 & 0.78 & 0.35 & 0.064 & 0.014 \\
\hline & & 1.61 & 1.16 & 0.74 & 0.33 & 0.058 & 0.015 \\
\hline & & 1.58 & 1.13 & 0.75 & 0.35 & 0.062 & 0.018 \\
\hline & RSD (\%) & 1.5 & 1.5 & 2.1 & 1.2 & 0.31 & 0.21 \\
\hline & 900 & 1.87 & 1.26 & 0.87 & 0.35 & 0.081 & 0.023 \\
\hline & & 1.86 & 1.23 & 0.81 & 0.35 & 0.082 & 0.022 \\
\hline & & 1.89 & 1.31 & 0.92 & 0.37 & 0.091 & 0.024 \\
\hline & RSD (\%) & 1.5 & 4.0 & 5.5 & 1.2 & 0.55 & 0.1 \\
\hline \multirow[t]{8}{*}{ Omethoate } & 600 & 0.19 & 0.15 & 0.13 & 0.11 & 0.041 & 0.031 \\
\hline & & 0.18 & 0.15 & 0.12 & 0.11 & 0.043 & 0.032 \\
\hline & & 0.20 & 0.14 & 0.13 & 0.12 & 0.039 & 0.028 \\
\hline & RSD (\%) & 1.0 & 0.58 & 0.58 & 0.58 & 0.20 & 0.21 \\
\hline & 900 & 0.21 & 0.16 & 0.14 & 0.10 & 0.058 & 0.041 \\
\hline & & 0.20 & 0.16 & 0.14 & 0.11 & 0.054 & 0.041 \\
\hline & & 0.22 & 0.17 & 0.13 & 0.15 & 0.059 & 0.046 \\
\hline & RSD (\%) & 1.0 & 0.58 & 0.58 & 2.6 & 0.26 & 0.29 \\
\hline
\end{tabular}

3

4 


\section{Table 6(on next page)}

Residues of dimethoate and its metabolite omethoate after the application of dimethoate three times during harvesting stage of growth the celery 
1

\begin{tabular}{|c|c|c|c|c|c|c|c|}
\hline \multirow{2}{*}{ Pesticide } & \multirow{2}{*}{$\begin{array}{c}\text { Dosage } \\
\text { (g a.i./ha) }\end{array}$} & \multicolumn{3}{|c|}{ Final residue $\left(\mathrm{mg} \mathrm{kg}^{-1}\right)$} & \multicolumn{3}{|c|}{ (Days after the last application) } \\
\hline & & 3 & 5 & 7 & 10 & 14 & 21 \\
\hline \multirow[t]{8}{*}{ Dimethoate } & 600 & 1.73 & 1.21 & 0.82 & 0.41 & 0.074 & 0.035 \\
\hline & & 1.73 & 1.22 & 0.80 & 0.43 & 0.075 & 0.031 \\
\hline & & 1.72 & 1.21 & 0.83 & 0.40 & 0.078 & 0.036 \\
\hline & RSD (\%) & 0.58 & 0.58 & 1.5 & 1.5 & 0.21 & 0.26 \\
\hline & 900 & 2.01 & 1.39 & 0.89 & 0.46 & 0.11 & 0.062 \\
\hline & & 1.98 & 1.39 & 0.91 & 0.47 & 0.12 & 0.063 \\
\hline & & 2.05 & 1.38 & 0.87 & 0.44 & 0.15 & 0.058 \\
\hline & RSD (\%) & 3.5 & 0.58 & 2.0 & 1.5 & 2.1 & 0.26 \\
\hline \multirow[t]{8}{*}{ Omethoate } & 600 & 0.21 & 0.19 & 0.14 & 0.11 & 0.062 & 0.033 \\
\hline & & 0.21 & 0.19 & 0.15 & 0.10 & 0.056 & 0.042 \\
\hline & & 0.22 & 0.20 & 0.13 & 0.11 & 0.061 & 0.039 \\
\hline & RSD (\%) & 0.58 & 0.58 & 1.0 & 0.58 & 0.32 & 0.46 \\
\hline & 900 & 0.22 & 0.18 & 0.15 & 0.11 & 0.071 & 0.047 \\
\hline & & 0.21 & 0.19 & 0.16 & 0.12 & 0.075 & 0.041 \\
\hline & & 0.22 & 0.18 & 0.14 & 0.11 & 0.081 & 0.048 \\
\hline & RSD (\%) & 0.58 & 0.58 & 1.0 & 0.58 & 0.5 & 0.38 \\
\hline
\end{tabular}

2 


\section{Table 7 (on next page)}

Chronic risk quotient (RQ) of total residualof dimethoate and omethoate (expressed as dimethoate) of different populations in China 
1

\begin{tabular}{|c|c|c|c|c|c|c|c|c|}
\hline \multirow{2}{*}{ Age (year) /Sex } & \multirow{2}{*}{$\begin{array}{c}\text { Body weight } \\
(\mathrm{kg})\end{array}$} & \multirow{2}{*}{$\begin{array}{c}\text { Vegetable intake }(\mathrm{F}) \\
\qquad\left(\mathrm{g} \mathrm{d}^{-1}\right)\end{array}$} & \multicolumn{3}{|c|}{ Median residue (STMR)* $\left(\mathrm{mg} \mathrm{kg}^{-1}\right)$} & \multicolumn{3}{|c|}{ chronic risk quotient (RQ) } \\
\hline & & & $10 \mathrm{~d}$ & $14 \mathrm{~d}$ & $21 \mathrm{~d}$ & $10 \mathrm{~d}$ & $14 \mathrm{~d}$ & $21 \mathrm{~d}$ \\
\hline 2-7/irrespective & 17.9 & 194.8 & 0.73 & 0.26 & 0.15 & 3.97 & 1.41 & 0.82 \\
\hline 8-12/irrespective & 33.1 & 272.4 & 0.73 & 0.26 & 0.15 & 3.00 & 1.07 & 0.62 \\
\hline 13-19/male & 56.4 & 396.7 & 0.73 & 0.26 & 0.15 & 2.57 & 0.91 & 0.53 \\
\hline 13-19/female & 50.0 & 317.9 & 0.73 & 0.26 & 0.15 & 2.32 & 0.83 & 0.48 \\
\hline $20-50 /$ male & 63.0 & 436.4 & 0.73 & 0.26 & 0.15 & 2.53 & 0.90 & 0.52 \\
\hline 20-50/female & 56.0 & 412.1 & 0.73 & 0.26 & 0.15 & 2.69 & 0.96 & 0.55 \\
\hline 51-65/male & 65.0 & 477.9 & 0.73 & 0.26 & 0.15 & 2.68 & 0.96 & 0.55 \\
\hline 51-65/female & 58.0 & 447.0 & 0.73 & 0.26 & 0.15 & 2.81 & 1.00 & 0.58 \\
\hline$>65 /$ male & 59.5 & 413.3 & 0.73 & 0.26 & 0.15 & 2.54 & 0.90 & 0.52 \\
\hline$>65 /$ female & 52.0 & 364.1 & 0.73 & 0.26 & 0.15 & 2.56 & 0.91 & 0.53 \\
\hline
\end{tabular}

2 *STMR is the median residue of dimethoate (sum of dimethoate and $3 *$ omethoate, expresses as dimethoate) of the standard test in Table 5 and 6. 
Table 8(on next page)

Acute risk quotient $(\mathrm{HQ})$ of total residualof dimethoate and omethoate (expressed as dimethoate) of different populations in China 


\begin{tabular}{|c|c|c|c|c|c|c|c|c|}
\hline \multirow{2}{*}{ Age (year) /Sex } & \multirow{2}{*}{$\begin{array}{l}\text { Body weight } \\
(\mathrm{kg})\end{array}$} & \multirow{2}{*}{$\begin{array}{l}\text { Vegetable intake }(\mathrm{F}) \\
\qquad\left(\mathrm{g} \mathrm{d}^{-1}\right)\end{array}$} & \multicolumn{3}{|c|}{ Highest residue $(\mathrm{HR})^{*}\left(\mathrm{mg} \mathrm{kg}^{-1}\right)$} & \multicolumn{3}{|c|}{ acute risk quotient (HQ) } \\
\hline & & & $10 \mathrm{~d}$ & $14 \mathrm{~d}$ & $21 \mathrm{~d}$ & $10 \mathrm{~d}$ & $14 \mathrm{~d}$ & $21 \mathrm{~d}$ \\
\hline 2-7/irrespective & 17.9 & 194.8 & 1.27 & 0.64 & 0.35 & 4.15 & 2.09 & 1.14 \\
\hline 8-12/irrespective & 33.1 & 272.4 & 1.27 & 0.64 & 0.35 & 3.14 & 1.58 & 0.86 \\
\hline $13-19 /$ male & 56.4 & 396.7 & 1.27 & 0.64 & 0.35 & 2.68 & 1.35 & 0.74 \\
\hline 13-19/female & 50.0 & 317.9 & 1.27 & 0.64 & 0.35 & 2.42 & 1.22 & 0.67 \\
\hline $20-50 /$ male & 63.0 & 436.4 & 1.27 & 0.64 & 0.35 & 2.64 & 1.33 & 0.73 \\
\hline $20-50 /$ female & 56.0 & 412.1 & 1.27 & 0.64 & 0.35 & 2.80 & 1.41 & 0.77 \\
\hline $51-65 /$ male & 65.0 & 477.9 & 1.27 & 0.64 & 0.35 & 2.80 & 1.41 & 0.77 \\
\hline 51-65/female & 58.0 & 447.0 & 1.27 & 0.64 & 0.35 & 2.94 & 1.48 & 0.81 \\
\hline$>65 /$ male & 59.5 & 413.3 & 1.27 & 0.64 & 0.35 & 2.65 & 1.33 & 0.73 \\
\hline$>65 /$ female & 52.0 & 364.1 & 1.27 & 0.64 & 0.35 & 2.67 & 1.34 & 0.74 \\
\hline
\end{tabular}

${ }^{*} \mathrm{HR}$ is the highest residue of dimethoate (sum of dimethoate and $6^{*}$ omethoate, expresses as dimethoate) of the standard test in Table 5 and 6. 